\title{
Elton Honores (ed), Lo fantástico en Hispanoamérica, Cuerpo de la Metáfora, Lima, 2011. ISBN: 978-612-45440-2-6
}

Egresado de la Universidad Nacional Mayor de San Marcos, Elton Honores (Lima, 1976) es profesor de la Universidad San Ignacio de Loyola, estudiante de posgrado en San Marcos e investigador especializado en el estudio de la narrativa fantástica en Hispanoamérica. Se graduó con una tesis donde analizó el proceso de la narrativa fantástica en el Perú poniendo énfasis en la obra de los representantes de la llamada generación del cincuenta. La investigación fue publicada recientemente con el nombre de Mundos imposibles. Lo fantástico en la narrativa peruana (2010). Ahora asistimos a la presentación del segundo libro de Honores: Lo fantástico en Hispanoamérica, donde él cumple el rol de coordinador de una edición que compila interesantes estudios en torno al tema en cuestión.

En realidad, por exceso de modestia, Honores eligió el mencionado título, pero el volumen quizá debió llamarse Lo fantástico en Latinoamérica, pues incluye dos notables estudios sobre la narrativa de ciencia ficción y el cuento fantástico en Brasil. En el primer ensayo ( Ortodoxos y heterodoxos: hacia un panorama de la narrativa fantástica peruana contemporánea (1980-2010) desde el sistema literario»), Honores cuestiona de qué manera «lo fantástico siguió siendo una producción clausurada para el sistema oficial» (p. 11). El investigador señala de qué modo, en los años ochenta del siglo XX, el realismo resulta siendo cuestionado como el único programa válido y ello posibilita la revaloración de otras perspectivas estéticas, en el cuento y la novela, que subrayaban la necesidad de apartarse del paradigma realista. Honores pone en tela de juicio la antología Nuevo cuento peruano (1984) de Luis Fernando Vidal y Antonio Cornejo Polar, porque estos autores conciben como algo negativo el influjo del cine, la televisión y las historietas en la nueva narrativa, cuando en realidad — -según Honores- «serán inevitablemente las grandes influencias de muchos de los narradores de los años 80 en adelante» (p. 15). Aquí quisiera reflexionar acerca de un tipo de crítica literaria que, algunas veces, valora un texto literario desde una perspectiva claramente temática e ideológica, y deja de lado los aspectos formales que son imprescindibles en un discurso narrativo o poético.

Honores arriesga una taxonomía de la narrativa fantástica contemporánea en el Perú. En la novela distingue dos tendencias: 1) La novela fantástico-clásica, donde se percibe poca experimentación 
en el ámbito formal. Los representantes de esta tendencia son Jeremy Torres, Augusto Murillo, Iván Bolaños, Hans Rothgiesser, David López Alfaro y Luis T. Moy, verbigracia; y 2) La novela fantásticoecléctica o el neohistoricismo fantástico, donde se observa un interés por la reconstrucción histórica, vale decir, se mezcla lo histórico y lo fantástico. Los principales exponentes son Carlos Herrera, Fernando Iwasaki, José Antonio Bravo, José Güich, Luis Enrique Tord, entre otros. En el cuento se precisan dos vertientes: 1) El cuento fantástico-clasicista, donde se reconoce la presencia de la ciencia ficción y lo fantástico expresado en lo gótico, el horror y el terror. Esta vertiente está representada por autores como Carlos Calderón Fajardo, José Güich, Jorge Eduardo Benavides, Pablo Nicoli Segura, por ejemplo; y 2) El cuento fantástico-ecléctico, que oscila entre un código realista y una apertura a lo onírico, la ciencia ficción, lo policial o lo fantástico. Dicha tendencia tiene como exponentes a Ricardo Sumalavia, Harry Belevan, Mario Bellatin, José Donayre, Enrique Prochazka, Carlos Yushimito, entre otros.

Víctor Bravo (en «La expresión de lo fantástico y la literatura venezolana»), afirma que lo fantástico, en la edad moderna, surge con el Romanticismo, aunque hay, sin duda, antecedentes en la literatura de la antigüedad y de la Edad Media. Subraya, además, que Horacio Quiroga (1878-1937) es el iniciador de lo fantástico moderno en América Latina. Por su parte, Julio Garmendia es el primer escritor venezolano que abre las puertas a lo fantástico en Venezuela a través de los relatos compilados en La tienda de muñecos (1927) y La tuna de oro (1951); sin embargo, Bravo destaca el aporte de otros escritores venezolanos como Arturo Uslar Pietri y Luis Britto García por el uso de la alegoría, el humor y la paradoja como recursos estilísticos.

Por su parte, Juan Carlos Toledano («Una cartografía de la ciencia-ficción cubana a través de la obra de Yoss»), señala cómo en Cuba la narrativa fantástica se opuso al credo del realismo socialista que venía de la Unión Soviética. Pone de relieve la importancia de la obra de Yoss, quien «es reflejo de toda una revolución interna en el estilo de la escritura de la cf (ciencia ficción, anotado nuestro) cubana que se explica dentro de las corrientes más contestatarias del movimiento cyberpunk [...], donde los bajos fondos, colmados de pobreza y violencia, junto con la opresión de los poderosos ocupan el espacio central, y donde sus personajes tratan de sobrevivir frente a este sistema aplicando su propia violencia, incluso si ésta se impone a sus propios cuerpos o es completamente fútil» (pp. 52-53).

María Cristina Batalha («Breve panorama del cuento brasileño») arriesga una taxonomía para ordenar el corpus del cuento fantástico brasileño y llega a precisar los siguientes tipos: 1) Cuento fantástico gótico (donde aparecen espectros, almas en pena y fantasmas); 2) Cuento fantástico maravilloso (donde se revelan hadas, magos y genios del bien y del mal); 
3) Cuento fantástico filosófico, metafísico (aquí se perciben percepciones extrasensoriales y apariciones a través de cuerpos opacos); 4) Cuento fantástico esotérico (marcado por lo paranormal, el misterio y lo esotérico); 5) Cuento fantástico paródico (que emplea el humor y parodia ciertos referentes del mundo real); 6) Cuento fantástico cruel (donde aparecen la perversión y la animalidad como rasgos centrales del ser humano); 7) Cuento fantástico absurdo-existencial (representado por los herederos de Franz Kafka y en cuyos relatos se observa la cosificación del hombre y la pérdida de su individualidad) y 8) Cuento fantástico moderno: meta-cuento: en este caso, «sobresalen los múltiples juegos metaficcionales y de estilo, la autoconsciencia el lenguaje y la auto-referencialidad de la propia literatura» (p. 88).

Hay otros ensayos muy interesantes en Lo fantástico en Hispanoamérica. Por ejemplo, Lola López Martín busca precisar la teoría de la ciencia ficción a partir de un enjuiciamiento de las ideas de Tzvetan Todorov contenidas en su Introducción a la literatura fantástica (1970). Braulio Tavares indaga por el origen de la ciencia ficción en Brasil a través de la noción de «novelas con inspiración científica» y resaltando el carácter fundacional de la obra de Jeronymo Monteiro. Juan Ramón Vélez García aborda el proceso de interiorización en dos cuentos de autores argentinos: «La mariposa» de Atilio Manuel Chiáppori y «La larga cabellera negra» de Manuel Mújica Láinez. Es de resaltar el aporte de los ensayos de Fernando Burgos, Marcia-
Espinoza Vera, Campo Ricardo Burgos, Fátima Nogueira, Pampa Olga Arán, Miguel Ángel Fernández, Yolanda Molina, Rodolfo Rorato Londero y David Roas. En dichos textos se observa el interés por comprender la naturaleza de lo fantástico tanto en su dimensión teórica como en el ámbito del proceso histórico de la literatura en lengua castellana o portuguesa.

Asimismo, se intenta pensar lo fantástico como un elemento que permite cuestionar las estructuras de poder y como una opción distinta de la realista o mimética. Por eso, en dichos ensayos se resalta la vigencia de la narrativa fantástica como una forma distinta, pero igualmente válida, de construir un universo representado a través de la literatura.

Pienso que Lo fantástico en Hispanoamérica es un libro valioso por varias razones: 1) revela un esfuerzo por dar un panorama de la literatura latinoamericana en lo que concierne a la narrativa fantástica; 2) manifiesta un interés por hacer una taxonomía del relato fantástico distinguiendo vertientes y tendencias; 3) evidencia una tentativa por teorizar en torno al problemático concepto de «lo fantástico»; y 4) enriquece nuestra visión de la literatura latinoamericana (pero también de la peninsular) al subrayar que la vertiente realista no es la única, sino que hay otras tendencias igualmente válidas y entre estas se encuentran la novela y el cuento fantásticos.

Por las razones antes expuestas, creo que este libro va a incentivar la discusión acerca de un tipo de literatura que, 
durante décadas, fue minusvalorada y que, hoy, emerge en el ámbito de la tradición narrativa con persistencia y originalidad. No me queda sino felicitar al profesor Elton Honores y a los autores de los ensayos compilados que arrojan luz acerca del recorrido fecundo de la narrativa fantástica en Latinoamérica.

Camilo Fernández Cozman Universidad Nacional Mayor de San Marcos, Perú camiloruben@gmail.com

\section{(c) $(7)($ )}

